\title{
Livelihood of Two Local Communities and Their Dependence on Forest Resources: A Case Study from Western Himalaya, Dachigam National Park, Jammu \& Kashmir, India
}

\author{
Khursid A. Khan ${ }^{1}$, Azra Musavi², Jamal A. Khan' ${ }^{1}$, Khursheed Ahmad ${ }^{3}$ \\ ${ }^{1}$ Department of Wildlife Sciences, Aligarh Muslim University, Aligarh, India \\ ${ }^{2}$ Department of Economics, Aligarh Muslim University, Aligarh, India \\ ${ }^{3}$ Faculty of Forestry, Sher-e-Kashmir University of Agriculture Science and Technology, Jammu \& Kashmir, India \\ Email: *khursid.amu@gmail.com
}

How to cite this paper: Khan, K.A., Musavi, A., Khan, J.A. and Ahmad, K. (2018) Livelihood of Two Local Communities and Their Dependence on Forest Resources: A Case Study from Western Himalaya, Dachigam National Park, Jammu \& Kashmir, India. Journal of Human Resource and Sustainability Studies, 6, 294-305.

https://doi.org/10.4236/jhrss.2018.64043

Received: July 21, 2018

Accepted: December 2, 2018

Published: December 5, 2018

Copyright $\odot 2018$ by authors and Scientific Research Publishing Inc. This work is licensed under the Creative Commons Attribution International License (CC BY 4.0).

http://creativecommons.org/licenses/by/4.0/

\section{(c) (i) Open Access}

\begin{abstract}
We examined the livelihood of two local communities (Kashmiri \& Gujjar) and their dependence on forest resources. New Theed and Mulnar are two villages situated at the northern-west boundary of Dachigam National Park (DNP). The population of New Theed is mainly belonging to the Kashmiri community while the Mulnar residents are from Gujjar community. Data were collected through random questionnaire survey from New Theed 101 and Mulnar 32 households (33\% and 46\%). It was found that about $21 \%$ and 93.75\% of households from Kashmiri and Gujjar communities were totally or partially dependent on DNP for their subsistence. With per capita fuel wood consumption of 1.09 and $4.04 \mathrm{~kg} / \mathrm{day}$, the average annual fuel wood consumption was found to be 0.39 and 3.92 metric ton per household of respective communities. According to household questionnaire survey, the average annual fuel wood collection was found to be lower $(0.21 \& 1.57$ metric tons/household) compared to the measured quantity (5.19 \& 7.32 metric tons/household) calculated on the basis of head loads being taken out of DNP. Moreover, $22 \%$ of Kashmiri community and $65 \%$ of Gujjar community collected green fodder from the forest for their livestock. Other resources collected from DNP were medicinal plants, honey, vegetables and fish, as well as timber. The harsh climatic conditions of the area, inappropriate supply of alternative fuels and bad condition of roads are the driving forces of higher fuel wood consumption for Gujjar community. Moreover, dependence on forest resources for subsistence is high among the Gujjar community due to high illiteracy rate and unemployment.
\end{abstract}




\section{Keywords}

Dachigam National Park, Dependence, Livelihood and Forest Resources

\section{Introduction}

The livelihoods of the most rural households throughout the developing countries depend on agriculture and forest resources [1]. The forests provide the natural asset to the rural and indigenous people. Dependence of people on forest resources continues to be important both the worldwide and in India. More than 1.6 billion (25\%) people of the world are dependent on forest resources for their livelihood [2]. However, in India, out of 1.3 billion people about 64 percent of the rural population ( 0.5824 billion) and 100 million tribe ( 0.1 billion) [3] depend on the forests for their sustenance.

India consists of the second largest population utilizing only $2.4 \%$ of total surface area of world. The enormous population living close to the forest with their livelihoods critically linked to the forest ecosystem. There are around 1.73 lakh villages located in and around forests [4]. People living in these forest fringe villages depend upon forest for a variety of goods and services. In India, 70\% population lives in rural areas and most of them have either agriculture or forest based economy. Forest and people are inextricably linked in India [5] and around 350 - 400 million (40\%) people are dependent on forest resources [6].

The people are depending on forest for Timber, fuel wood, fodder, fruits, flowers, tuber, roots and leaves for food and medicines and non-timber forest products (NTFPs). However, the anthropogenic pressure on forests is unsustainable and can cause forest degradation [7] [8] [9] [10] [11] and together with immense overgrazing, can reduce carrying capacity [9] [12] [13].

Fuel wood and fodder collection along with overgrazing are considered to be the cause of deforestation where human habitation is situated in and around forested landscapes and herd of migratory livestock is also dependent on these forested landscapes. India is no exception. According to ICFRE [14], it is estimated that India's forests support 270 million livestock against the carrying capacity of 30 million. $78 \%$ of India's forests are considered to be affected by livestock grazing; out of this, 18 percent are highly affected, while 31 percent are affected with medium intensity of grazing and 29 percent are affected with low intensity of grazing [4] [15].

The large livestock population also results in huge collection of tree fodder, which affects the forest quality adversely. Due to the vast population dependen$\mathrm{cy}$, overexploitation of the forest resources and unsustainable harvest practice degraded the forest ecosystem of India. Moreover, a significant number of tribal populations still live in its forested regions [16]. DNP is the only habitat of the critically endangered Hangul or Kashmir Stag (Cervus hanglu hanglu). Over the years, various studies have pointed to the shrinking of Hangul's habitat in coniferous forests and alpine meadows of Kashmir [17] [18] [19] as these areas have 
been occupied by livestock, nomads and migratory graziers [20]. Consequently, Hangul is considered to have disappeared from most of its former ranges. This study is concerned with the impact of dependence of local communities on the forests of DNP. Such study on dependence of communities on these forests resources and factors affecting this dependence is scarce. Therefore, this study is conducted to quantify the fuel wood and fodder collection and utilization by two communities living at the boundary of Dachigam National Park.

\section{Materials and Methods}

\subsection{Study Area}

The study area is a only remaining habitat of the critically endangered Red deer (Cervus hanglu hanglu) and the dependence of these communities build up a great pressure on the wild animals. The name of the park comes from the Kashmiri word Dah which means 10, chi means area and gam means village so "ten villages". Before the existence of the park there were 10 villages inside which were later relocated outside due to the formation of a game reserve or "rakh" by the Maharaja of Jammu and Kashmir and served as a hunting reserve for the Maharaja. The name of the National Park was given in the memory of these 10 villages. DNP is located to the north-east of Srinagar in Kashmir Valley. It covers an area of $141 \mathrm{~km}^{2}$ and lies between $34^{\circ} 05^{\prime}-34^{\circ} 11^{\prime} \mathrm{N}$ and $74^{\circ} 54^{\prime}-75^{\circ} 09^{\prime} \mathrm{E}$ in Zanskar mountain range of North-West Himalayan biogeographic Zone (2A) of India [21]. DNP is an important catchment area for Dal Lake and the only source of fresh water for Srinagar. The National Park is surrounded by five Conservation Reserves (Dara block of the Sindh forest Division in the north, Brain Block, Khrew and Tral ranges of Forest Plantations Divisions in the south, Harwan village and Harwan reservoir in the west and Lidder forest Department in the east). The south-east Dachigam is connected to Overa-Aru Wildlife Sanctuary. The DNP comes under two wildlife divisions viz., the Central and South Wildlife Divisions and is divided broadly into Upper and Lower Dachigam. DNP was a hunting reserve or of the Maharaja of Jammu and Kashmir from 1910 until 1947, after that its management was handed over to Department of Hospitality and Protocol (Fisheries Department, Directorate of game preservation) and subsequently to the Forest Department. It was managed under the Wildlife wing of Forest Department and later Dachigam was declared as a sanctuary by state order no. 276/C in 1951 [22] [22]. Dachigam Wildlife sanctuary was upgraded to National Park by the Government of Jammu and Kashmir order on 4 February 1981 (state order no. FST/20). The management of Dachigam National Park (Figure 1) is handed over to the newly formed Department of Wildlife Protection, Jammu and Kashmir 1982 after separation from Forest Department. The park is divided into two administrative unit Lower and Upper Dachigam which are administered by Central and South Wildlife Division respectively. Now a day it is managed in IUCN category-II (National Park). DNP is surrounded by many conservation reserves which are contiguous to the boundaries. 


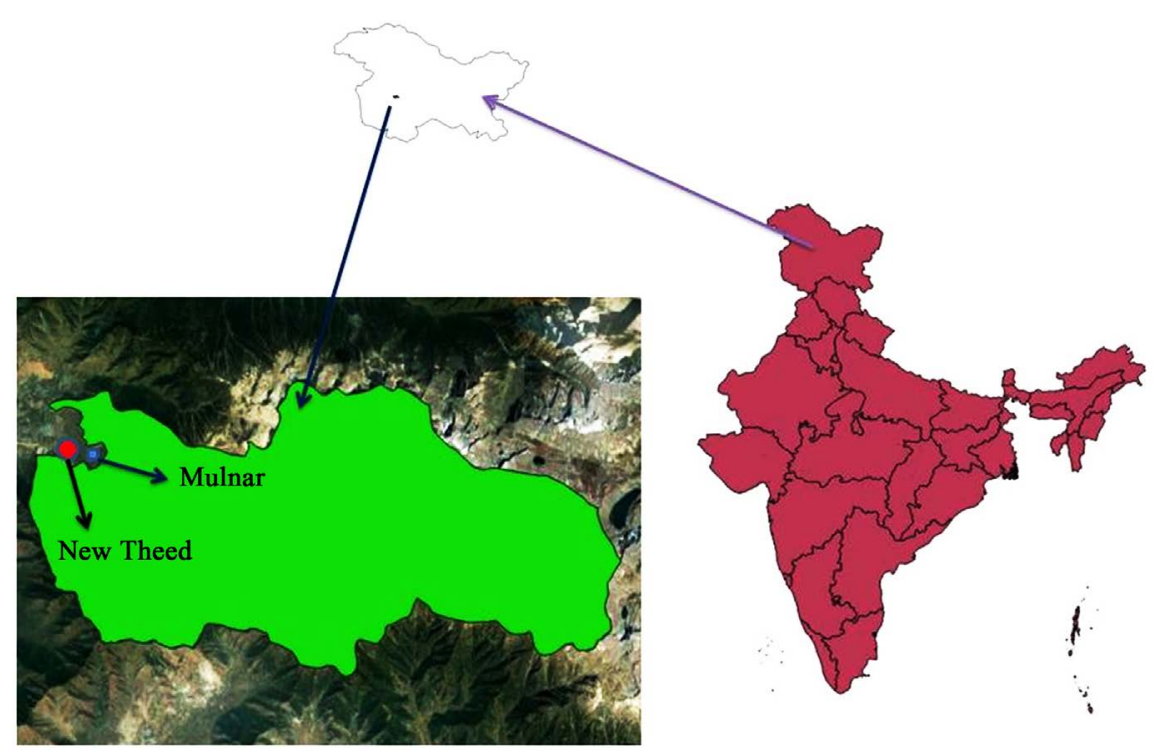

Figure 1. Location map of villages along with Dachigam national park.

There are 32 villages which are located on the periphery of Dachigam [24]. Managing wildlife has become challenging task due to these villages. There are 11 types of forest and grassland categories found in the DNP. Plant species such as Posh (Parrotiopsis jacquemontiana), maple (Acer caesium), mulberry (Morus alba) and walnut (Juglans regia), and conifers such as blue pine (Pinus wallichiana), spruce (Picea smithiana) and fir (Abies pindrow) are common in the low-altitude areas of the park [25]. The high altitude area has sub-alpine forest interspersed with grasslands, and merges into snow-clad peaks over $3500 \mathrm{~m}$. The grasses like Themeda anathera, Poa annua, Cynodon, and Degetaria were most common grasses found in Dachigam.

Dachigam has diverse fauna; in addition to Kashmir red deer, other rare large mammals found in the area include musk deer (Moschus chrysogaster), serow (Capricornis sumatraensis), Asiatic black bear (Ursus thibetanus), brown bear (Ursus arctos) and common leopard (Panthera pardus). The occurrence of the snow leopard (Panthera uncia) requires confirmation. The other meso-mammals found in the area are Himalayan grey langur (Semnopithecus ajax), red fox (Vulpes vulpes), golden jackal (Canis aureus), small Indian civet (Viverricula indica) and yellow-throated marten (Martes flavigula) [26] [27].

\subsection{Methods}

The data were collected on the socio economic parameters from Kashmiri (101) and (32) Gujjar households in New Theed and Mulnar villages. The data were collected through stratified random sampling [28] to select households in the sample villages to collect primary socio-economic data on demographic structure of the households, educational status, occupational pattern, size of land holding, cropping pattern, livestock population. Quantification of biomass extraction by these two communities was done using the data collected from sam- 
ple households (Survey). Data were also collected on the quantity of extracted biomass used for domestic consumption. Households were asked about the fuel wood, fodder and other Non timber forest product collection and quantity of biomass that they extracted annually from DNP. The head loads were also weighed at the entry and exit points of the park boundary to know the actual amount of fuel wood collection. Along with this a certain weighed amount of their own fuel wood was given to the households and said to use that given fuel wood [sometimes the researcher (KAK) stay in their house to see the actual consumption of fuel wood] after their one day consumption remaining fuel wood were again weighed to know the precise amount of fuel wood consumption. In addition to the household survey, seasonal observations were also made at the entry points from the villages into the forest to quantify the number of people and livestock using the forest in different seasons. Both qualitative and quantitative data were collected using open and close-ended questions. Moreover, fixed response questions were included for easy interpretation and analysis. The questionnaire was tested during reconnaissance survey of the study area and appropriate changes were made accordingly.

\section{Results}

The New Theed and Mulnar are among the 32 villages situated at the boundary of DNP. Both the villages are situated almost same distance from the park boundary. The population of New Theed is mainly belongs to the Kashmiri community while the resident of Mulnar is Gujjar. The New Theed comes under the Harwan locality which consists of about 2348 households [29]. Mulnar is a small village situated at the rugged terrain of the mountain. The data was collected from New Theed 101 households (Out of 300) and Mulnar 32 households (Out of 69). On the basis of dependence it was estimated that $21 \%$ households from Kashmiri community and $93.75 \%$ households of Gujjar community are totally of partially dependent on DNP for their subsistence. The demographic data collected from these two communities indicates that Kashmiri community has smaller family size $5.96 \pm 0.26$ in comparison to Gujjars $6.75 \pm 0.4$. The sex ratio (male:female) was found to be 0.9 and 1.22 of the of Kashmiri and Gujjar community respectively. Jammu and Kashmir state literacy rate was estimated $65.57 \%$ and Srinagar district literacy rate was found to be $71.21 \%$. Moreover the average literacy rate was estimate to be $47.82 \%$ for Kashmiri community and $37.7 \%$ in Gujjar community.

The occupational status (Table 1) of these two communities indicate that Maximum Kashmiri people were government servant (37.03\%) followed by the unemployed or Labourer (33.33\%) and with equal percentage (14.81\%) of people are farmer and in private sector respectively. Moreover the in Gujjar community most of the people were unemployed (59.37\%) followed by farmer (18.75\%), Government servant (12.5\%) and 9.37\% people were engaged in private sector.

Land holding pattern of two communities (Table 2) indicates that most of the Kashmiri households were landless (42.59\%), in comparison to Gujjars (15.62\%), 
Table 1. Comparative occupation status of Kashmiri and Gujjar communities.

\begin{tabular}{ccccc}
\hline Community & Farmer & Gov. serv. & Unemployed/Labour & Private Job \\
\hline Kashmiri & 14.81 & 37.03 & 33.33 & 14.81 \\
Gujjar & 18.75 & 12.5 & 59.37 & 9.37 \\
\hline
\end{tabular}

The data is come from the questionnaire survey.

Table 2. Land holding pattern of Kashmiri and Gujjar communities.

\begin{tabular}{ccccccc}
\hline Community & Landless & Marginal & Small & Semi medium & Medium & Large \\
\hline Kashmiri & 42.59 & 11.11 & 7.4 & 16.66 & 9.25 & 12.96 \\
Gujjar & 15.62 & 12.5 & 31.25 & 18.75 & 6.25 & 15.62 \\
\hline
\end{tabular}

The data is come from the questionnaire survey.

while $31.25 \%$ Gujjar households had small land holding in comparison to Kashmiri community (7.4\%).

The cropping pattern of Kashmiri households (Figure 2) indicates that the most of the households were found to be involved in horticulture (49\%) followed by paddy $(29 \%)$, vegetables $(9 \%)$, maize $(7 \%)$ and other $(6 \%)$. However the cropping pattern of Gujjar community (Figure 3) indicates that most of the households (85\%) were found to be involved in horticulture followed by maize, vegetables $(6 \%)$ respectively and other $(3 \%)$.

The data on monthly average fuel wood collection and consumption were estimated on the basis of questionnaire survey and it was found that the average fuel wood collection was found to be $23.33 \mathrm{~kg} /$ month for Kashmiri community and $175 \mathrm{~kg} / \mathrm{month}$ in Gujjar community. While the average fuel wood consumption was found to be $1.09 \mathrm{~kg}$ /day/household for Kashmiri community and 4.04 $\mathrm{kg} /$ day/household for Gujjar community.

The measured average fuel wood collection was found to be 576.82 and 813.46 $\mathrm{kg} /$ household/ month for Kashmiri and Gujjar communities respectively. The measure data exaggerated more than the questionnaire data because of two reasons. Firstly people don't weight the fuel wood and secondly they don't want to tell the fact about the fuel wood collection.

In the same way actual amount of fuel wood consumption was estimated to be $7.05 \mathrm{~kg} /$ day/household for Kashmiri community and $10.91 \mathrm{~kg} /$ day/Household for Gujjar community.

The average annual fuel wood collection and consumption among the questionnaire data and measured data was given in Table 3. The difference among the collection and consumption was found to be high in measured data because people use wood as a winter fire and in "hammams" in winters.

The Mann Whitney $U$ test was used to see the difference between the fuel wood collection among the Kashmiri and Gujjar Communities. The result was found significant $\mathrm{U}=82.5$ and $\mathrm{P}=0.041(\mathrm{P}<0.5)$ among the fuel wood collectors. 


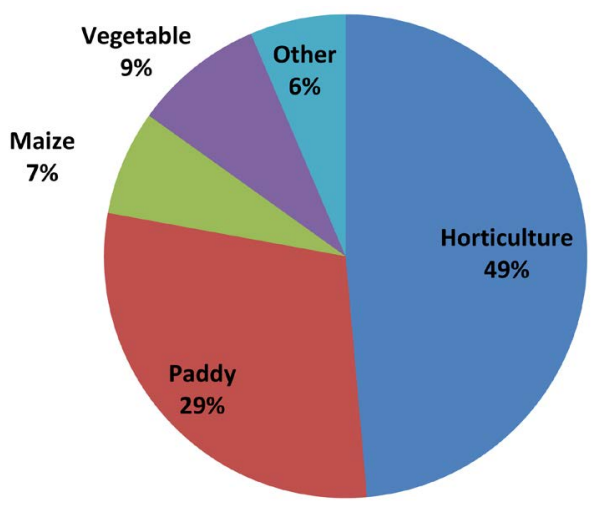

Figure 2. Cropping pattern of Kashmiri community.

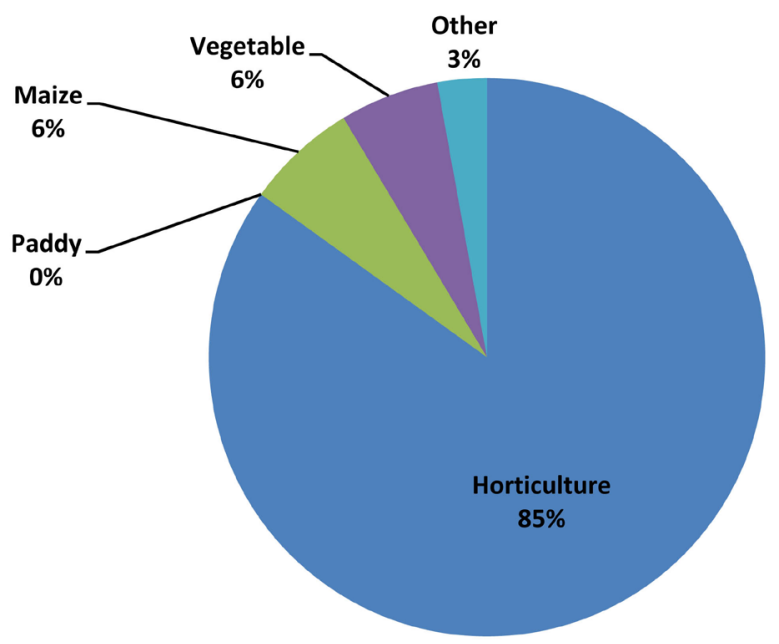

Figure 3. Cropping pattern of Gujjar community.

Table 3. Comparative study of annual fuel wood collection and consumption on Questionnaire data and measurement data.

\begin{tabular}{ccccc}
\hline \multirow{2}{*}{ Community } & \multicolumn{2}{c}{ Questionnaire Survey Data } & \multicolumn{2}{c}{ Measurement Data } \\
\cline { 2 - 5 } & $\begin{array}{c}\text { Annual } \\
\text { Fuel wood } \\
\text { collection/ } \\
\text { Household }\end{array}$ & $\begin{array}{c}\text { Annual } \\
\text { Fuel wood } \\
\text { consumptions/ } \\
\text { Household }\end{array}$ & $\begin{array}{c}\text { Actual fuel } \\
\text { wood Collection/ } \\
\text { Household } \\
\text { (Annual) }\end{array}$ & $\begin{array}{c}\text { Actual fuel } \\
\text { wood consumption/ } \\
\text { Household } \\
\text { (Annual) }\end{array}$ \\
\hline Kashmiri & 0.21 & 0.29 & 5.19 & 3.01 \\
Gujjar & 1.57 & 1.45 & 7.32 & 4.18 \\
\hline
\end{tabular}

${ }^{\star}$ The data is come from the questionnaire survey while the measured data (fuelwood collection) was collected from the entry and exit points of the park boundary and consumption data was come from certain weighed amount of fuel wood given to the households and after their one day consumption remain fuel wood were again weighed to know the precise amount of fuel wood consumption.

According to questionnaire survey about $22 \%$ household of Kashmiri community and $65 \%$ household of Gujjar community were estimated to engage in fodder collection from DNP.

However, the data collected on the entry and exit points indicate that $37 \%$ household of Kashmiri community and $90.6 \%$ of Gujjar community was found 
to engage in fodder collection from the DNP.

The average fodder collection was found to be $56.57 \mathrm{~kg} /$ day/household for Kashmiri community and $58.55 \mathrm{~kg} /$ day/household for Gujjar community.

Beside these product people extract other NTFP like walnut, medicinal plants, honey and vegetable from DNP.

\section{Discussion}

The forests embrace the biological diversity as well as provide the natural resources to the human being. Besides providing such benefits the forests are still degrading day by day due to exponential population growth, poverty and less awareness about the ecosystem services. More than 350 million people were living inside or on the fringes of forests across the world, out of which 60 million were largely dependent for sustenance [15]. Forests in most developing countries are under anthropogenic pressure from resource use by marginalized communities for subsistence as well as due to demand for forest products throughout the world resulting in over exploitation of forests [4] [6] [11] [30]. The condition is considered more perilous in Asia and Africa, where loss of forests during a ten year period in the later part of the $20^{\text {th }}$ century was estimated to 163 million ha, of which 154 million ha or 94.5 percent was in the tropics alone [31].

The demographic data indicates that Kashmiri community has smaller family size $5.96 \pm 0.26$ in comparison to Gujjars $6.75 \pm 0.4$. This is because of the low literacy rate among the Gujjar community. The sex ratio (male:female) was found to be 0.9 and 1.22 of the of Kashmiri and Gujjar community respectively. Jammu and Kashmir state literacy rate was estimated $65.57 \%$ and Srinagar district literacy rate was found to be $71.21 \%$. Srinagar is one among the leading literacy district of Jammu and Kashmir [29]. Moreover the average literacy rate was estimated to be $47.82 \%$ for Kashmiri community and $37.7 \%$ in Gujjar community. This figure is less than the district as well as the state literacy rate [29]. The literacy rate of Gujjar's is found low because of unavailability of primary education and less feasibility of road network in the village. Recently the Government Primary school has been established but the children presence was found very low. Out of $37.7 \%$ literate in Gujjar community most of the literate were below 16 year age. The condition of New Theed village is better because of the presence of primary as well as Middle school in this village.

In occupational status more Kashmiri people were government servant $37.03 \%$ followed by the unemployed or Laborer $(33.33 \%)$ and equal percentages (14.81\%) of people are farmer and in private sector respectively. Moreover, in the Gujjar community most of the people were unemployed $(59.37 \%)$ followed by farmer (18.75\%), Government servant (12.5\%) and $9.37 \%$ people were engage in private sector. The Kashmiri community was involved in more government services due to more literacy rate. The Gujjar in Mulnar village were recent settler and are migrated from different part of the Jammu and Kashmir and settled in Mulnar village, while the New Theed is an old revenue village in comparison 
to Mulnar [24].

Land holding pattern among the two communities indicates that most of the Kashmiri households were landless (42.59\%), in comparison to Gujjars (15.62\%), According to people Maharaja did not allotted land for farming to the relocated people from the DNP. That is why Kashmiri people are more landless than the Gujjars. While the Gujjars were bought the land for their settlement so they have small land holdings.

The horticulture is a backbone of Jammu and Kashmir economy and it does generate the major part of revenue to the state economy [32]. The cropping pattern of Kashmiris as well as Gujjars households indicates that the most of the households were found to be involved in horticulture $49 \%$ and $85 \%$ respectively.

Fuelwood consumption in India is 173,412 Ktons [33], with 62 percent derived from forests [34]. The data on monthly average fuel wood collection and consumption were estimated on the basis of questionnaire survey and it was found that the average fuel wood collection was found to be $23.33 \mathrm{~kg} / \mathrm{month}$ for Kashmiri community and $175 \mathrm{~kg} /$ month in Gujjar community. While the average fuel wood consumption was found to be $1.09 \mathrm{~kg} /$ day/household for Kashmiri community and $4.04 \mathrm{~kg} /$ day/household for Gujjar community. This is because of the alternative use by Kashmiri people while the Gujjar community did not use any alternative to fuelwood except the electric heater. Unavailability and high price of LPG is the reason for not using the alternative. People were willing to use the Kerosene stoves but due to irregular and insufficient supply compel them to use fuelwood.

In conclusion, the Gujjar communities were found to be more dependent on forest resources in comparison to Kashmiris. This unsustainable dependence leads to the forest degradation [35]. Other field based studies on patterns of collection of forest products and their impact on local forests in India, have also found that local livelihood dependence results in degradation [7] [9] [10] [11] [12] [36]. More than $40 \%$ of India's poor population lives on forest fringes [4] and depends upon forests for a variety of goods and services. Therefore, with such a huge population and extensive dependence pattern, any over exploitation and unsustainable harvest practices can potentially degrade India's forests [11] [30].

\section{Conclusion}

The Gujjar community is poorer, illiterate and has less employment in comparison to the Kashmiri community. This is the main reason that they are more dependent on the forest recourses. The Kashmiri community is richer, literate and has more employment that is why they are less dependent on forest resources for their subsistence. If the dependence will persist long time, it will cause serious problem for the only persisting population of critically endangered Kashmir Red deer. The following recommendation must be implemented to reduce the dependence of people from the Dachigam National Park. 


\section{Recommendations}

The community forest should be developed around the park boundary to minimize the fuel wood dependence from the forest. The villagers should be allowed to collect fodder from the sheep breeding farm in a regulated manner. Sericulture, Apiculture and Mushroom farming must be promoted in these two villages to reduce the dependence on forest for their livelihood. Awareness programme must be organized in the villages to aware the people about the value of forest and sustainable livelihood. Education and Job opportunity should be provided more to the Gujjar community so that their dependence could be minimized. Alternative to fuel wood should be provided to both the community as subsidies rates (LPG, Kerosene, Solar cooker etc.). A connecting road network must be constructed for the transportation, especially for Mulnar village. Tree felling along with other disturbance must be checked for protection of fauna and flora of DNP.

\section{Acknowledgements}

We are thankful to the Ministry of Environment, Forestry and Climate Change for the funding. We would like to extend our thanks to the economics and wildlife department Aligarh Muslim University for their support. We would like to thanks forest official of Jammu and Kashmir wildlife protection department, especially Tahir Shawl, Imtiyaz A. Lone, Rauf Zargar and others for their immense support in field visit. KAK is thankful to Maulvi Mohammad, Ejaj, Belal, G.M. Dar, Shabbir A. Lone for their support in data collection.

\section{Conflicts of Interest}

The authors declare no conflicts of interest regarding the publication of this paper.

\section{References}

[1] Caplow, S., Jagger, P., Lawlor, K. and Sills, E. (2011) Evaluating the Land Use and Livelihood Outcomes of Early Forest Carbon Projects: Lessons for REDD+. Environmental Science \& Policy, 14, 52-167. https://doi.org/10.1016/j.envsci.2010.10.003

[2] SFRI. (2011) State of Forest Report India. Ministry of Environment and Forest, Dehradun, 286.

[3] Lynch, O.J. (1992) Securing Community Based Tenurial Rights in the Tropical Forests of Asia-An Overview of Current and Prospective Strategies. Issues in Development, World Resources Institute, Washington DC, 12.

[4] MoEF. (2006) Report of the National Forest Commission. Ministry of Environment and Forests, Government of India, New Delhi, 421.

[5] Kothari, A., Pande, P., Singh, S.D. and Variava, D. (1989) Management of National Parks and Sanctuaries in India: A Status Report. Indian Institute of Public Administration, New Delhi, 298.

[6] MoEF. (2009) State of Environment Report. Ministry of Environment and Forest, Government of India, New Delhi, 126. 
[7] Maikhuri, R.K., Rao, K.S. and Semwal, R.L. (2001) Changing Scenario of Himalayan Agroecosytem: Loss of Agrobiodiversity, an Indicator of Environmental Change in Central Himalaya, India. Environmentalist, 20, 23-39. https://doi.org/10.1023/A:1010638104135

[8] Puyravaud, J.-Ph. and Garrigues, J.P. (2002) L'agriculteur ou la forêt? Systèmes agraires, prélèvements et consequences écologiques sous la crête des Ghâts (district de Shimoga). In: Pouchepadass, J. and Puyravaud, J.-Ph., Eds., L'homme et la Forêt en Inde, Institut Français de Pondichery-Karthala, 167-234.

[9] Sagar, R. and Singh, J.S. (2004) Local Plant Species Depletion in a Tropical Deciduous Forest of Northern India. Environmental Conservation, 31, 55-62. https://doi.org/10.1017/S0376892904001031

[10] Arjunan, M., Puyravaud, J. and Davidar, P. (2005) The Impact of Resource Collection by Local Communities on the Dry Forests of the Kalakad-Mundanthurai Tiger Reserve. Tropical Ecology, 46, 135-144.

[11] Davidar, P., et al. (2010) Assessing the Extent and Causes of Forest Degradation in India: Where do we Stand? Biological Conservation, 43, 2937-2944.

https://doi.org/10.1016/j.biocon.2010.04.032

[12] Silori, C.S. and Mishra, B.K. (2001) Assessment of Livestock Grazing Pressure in and around the Elephant Corridors in Mudumalai Wildlife Sanctuary, South India. Biological Conservation, 10, 2185-2195.

[13] Madhusudan, M.D. (2005) The Global Village: Linkages between International Coffee Markets and Grazing by Livestock in a South Indian Wildlife Reserve. Conservation Biology, 19, 411-420. https://doi.org/10.1111/j.1523-1739.2005.00330.x

[14] ICFRE. (2001) (Indian Council of Forestry Research and Education). Forestry Statistics of India 1987-2001, Dehradun, 234.

[15] World Bank. (2006) India: Unlocking Opportunities for Forest Dependent People in India. Report in World Bank, South Asia Region, 85.

[16] Saha, A. and Guru, B. (2003) Poverty in Remote Rural Areas in India: A Review of Evidence and Issues. GIDR Working Paper No. 139, Gujarat Institute of Development Research, Ahmedabad, 69.

[17] Schaller, G.B. (1969) Observations on Hangul or Kashmir Stag (Cervus elaphus hanglu). Journal of the Bombay Natural History Society, 66, 1-7.

[18] Kurt, F. (1978) Threatened Deer. Proceedings of IUCN Threatened Deer Programme. Kashmir Deer (Cervus elaphus hanglu) in Dachigam. IUCN Specialist Group Publications, 87-109.

[19] Ahmad, K. (2006) Aspects of Ecology of Hangul (Cervus elaphus hanglu) in Dachigam National Park, Kashmir, India. PhD Thesis, Forest Research Institute (Deemed University) Dehradun, Uttaranchal, 205.

[20] Khan, K.A., Musavi, A. and Ahmad, K. (2016) Assessment of Anthropogenic Pressure and Its Impact on Forest and Grassland Ecosystem of Dachigam National Park. 1st Annual Report, Department of Economics, Aligarh Muslim University, Aligarh, 59.

[21] Rodgers, W.A., Panwar, H.S. and Mathur, V.B. (2000) Wildlife Protected Area Network in India: A Review (Executive Summary). Wildlife Institute of India, Dehradun.

[22] Holloway, C.W. (1971) The Hangul in Dachigam: A Census. Oryx, 10, 373-382. https://doi.org/10.1017/S0030605300009121

[23] Holloway, C.W. and Wani, A.R. (1971) Management Plan for Dachigam Sanctuary: 
1971-75. Cyclostyled (Mimeo), 185.

[24] Naqash, R.Y. and Sharma, L. (2011) Management Plan for Dachigam National Park (2011-2016). Jammu \& Kashmir, Srinagar, 172.

[25] Shameem, S.A. and Kangroo, I.N. (2011) Comparative Assessment of Edaphic Features and Phytodiversity in Lower Dachigam National Park, Kashmir Himalaya, India. African Journal of Environmental Science and Technology, 5, 972-984.

[26] Ahmad, K., Sathyakumar, S. and Qureshi, Q. (2009) Conservation Status of the Last Surviving Wild Population of Hangul or Kashmir Deer (Cervus elaphus hanglu) in Kashmir, India. Journal of the Bombay Natural History Society, 106, 245-255.

[27] Charoo, S.A., Naqash, R.Y. and Sathyakumar, S. (2011) Monitoring of Hangul in Dachigam Landscape: Technical Report. Department of Wildlife Protection, J\&K Govt. and Wildlife Institute of India, Dehradun, 78.

[28] Clarke, M.I. (1986) Activity Modelling a Research Tool or a Practical Planning Technique? In: Behavioral Research for Transport Policy, VNU Science Press, Utrecht, 123.

[29] Census (2011) Census of India. Jammu and Kashmir Population Census Data. Ministry of Home Affair Government of India, New Delhi.

[30] FSI (2011) Forest Survey of India. India State of Forest Report, Ministry of Environment and Forests, Government of India, New Delhi, 268.

[31] FAO (1995) Food and Agriculture Organization. Non-Wood Forest Products in Nutrition. FAO/GOI Expert Consultation on Non-Wood Forest Products, Yogyakarta, 17-27 January 1995, 1-75.

[32] Malik, Z.A. and Choure, T. (2014) Horticulture Growth Trajectory Evidences in Jammu and Kashmir (A Lesson for Apple Industry in India). Journal of Business Management and Social Science Research, 3, 45-49.

[33] RWEDP (1997) Regional Study on Wood Energy Today and Tomorrow in Asia. Field Document 50, Regional Wood Energy Development Programme in Asia, Bangkok, 168.

[34] Leach, G. (1987) Household Energy in South Asia. Elsevier Applied Science Publication, London.

[35] Aggarwal, A., Paul, V. and Das, S. (2009) Forest Resources: Degradation, Livelihoods, and Climate Change. In: Datt, D. and Nischal, S., Eds., Looking Back to Change Track, TERI, New Delhi, 219, 91-108.

[36] Mishra, P.C., Tripathy, P.K., Behera, N. and Mishra, K. (2008) Socioeconomic and Socio-Ecological Study of Sambalpur Forest Division, Orissa. Journal of Human Ecology, 23, 135-146. https://doi.org/10.1080/09709274.2008.11906064 